\section{WIFO}

ÖSTERREICHISCHES INSTITUT FÜR WIRTSCHAFTSFORSCHUNG
WORKING PAPERS
High-growth Firm Shares in Austrian Regions: The Role of Economic Structures

Klaus S. Friesenbichler, Werner Hölzl 


\title{
High-growth Firm Shares in Austrian Regions: The Role of Economic Structures
}

\section{Klaus S. Friesenbichler, Werner Hölzl}

WIFO Working Papers, No. 595

March 2020

\begin{abstract}
This paper explores the structural determinants of high-growth firm shares in Austrian regions. The regional level of analysis allows to uncover regularities which are not detectable in firm-level studies. We find that lower mobility barriers, firm exits and technological opportunities, measured by digitalisation intensities, and, to a lesser extent, agglomeration effects are associated with a larger share of high-growth firms. The results suggest that comparisons of shares of high-growth firms across countries and regions should consider differences in the industrial structures together with the often-emphasised differences in policies and regulations.
\end{abstract}




\section{High-growth firm shares in Austrian regions: The role of economic structures}

$9^{\text {th }}$ March 2020

This is a draft version. The final paper will be published in a forthcoming issue of Regional Studies.

Klaus Friesenbichler

Austrian Institute of Economic Research [WIFO], Arsenal, Object 20, 1030 Vienna, Austria,

Klaus.Friesenbichler@wifo.ac.at, phone: +43-1-7982601-296, fax: +43-1-7989386

Werner Hölzl

Austrian Institute of Economic Research [WIFO], Arsenal, Object 20, 1030 Vienna, Austria,

Werner.Hoelzl@wifo.ac.at, phone: +43-1-7982601-472, fax: +43-1-7989386

\section{Acknowledgements:}

We are grateful to Alexandros Charos and Kathrin Hofmann for their assistance with the data handling. Previous versions of this paper have benefited from comments received at a seminar at the Max Planck Institute for Economics in Jena in May 2014, the 54 ${ }^{\text {th }}$ ERSA Conference in St. Petersburg in August 2014 and an IEB Seminar in Barcelona in November 2015. Klaus Friesenbichler acknowledges financial support from the GROWINPRO project on Growth Welfare Innovation Productivity that has received funding from the European Union Horizon 2020 research and innovation programme under grant agreement No. 822781. 


\begin{abstract}
This paper explores the structural determinants of high-growth firm shares in Austrian regions. The regional level of analysis allows to uncover regularities which are not detectable in firm-level studies. We find that lower mobility barriers, firm exits and technological opportunities, measured by digitalisation intensities, and, to a lesser extent, agglomeration effects are associated with a larger share of high-growth firms. The results suggest that comparisons of shares of high-growth firm across countries and regions should consider differences in the industrial structures together with the often-emphasised differences in policies and regulations.
\end{abstract}

JEL Classifications: D22, L25, R11

Keywords: high growth firms, industrial structure, ICT; Austria, variety; NUTS-3 


\section{High-growth firm shares in Austrian regions: The role of economic structures}

\section{Introduction}

High-growth firms (HGFs) are important drivers of employment and economic dynamics and are perceived as the key bearers of creative destruction and structural change (e.g., Shane, 2009; Coad et al., 2014; Birch \& Medoff, 1994). Policy makers' interest and the increasing availability of representative large-scale datasets have stimulated research on the determinants of HGFs. Even though the focus of many policy makers is regional development, most studies on HGFs have focused on the firm level.

Another strand of economic literature emphasises that cross-country differences in productivity are linked to the heterogeneity of firm performance and the efficiency of the market selection process (e.g., Bartelsman et al., 2013; Andrews \& Cingano, 2014). Firm turbulence has been found to be more pronounced in regions with higher aggregate growth, a highly qualified workforce and more unrelated variety in the regional industrial structure (Duschl, 2016). The presence of HGFs may therefore mirror dynamism and reallocation opportunities. These differences in the efficiency of the market selection are likely determined by institutional and structural factors.

In this paper, we study the impact of the regional industrial structure on HGF shares. We use data for Austria's 35 NUTS-3 regions for six three-year periods covering the time span from 1995 to 2012. We observe a persistence of HGF shares across regions, which has been found to be largely absent in firm-level studies (Daunfeldt \& Halvarsson, 2015; Bianchini et al., 2017). This already suggests that the regional level of analysis of HGF shares allows us to uncover different regularities than the study of the HGF status at the firm level. We focus on the question of whether structural regional factors explain differences in HGF shares across regions. 
Differences in economic structure are captured by different indicators: the industrial portfolio, mobility barriers, firm turnover and specialisation patterns with respect to ICT-intensive industries. Our results suggest that differences in HGF shares at the regional level are related to technological (ICT) and economic differences in regional industrial structures.

We provide two interlinked contributions to the literature:

First, we make a conceptual point with respect to the level of analysis. Firm-level studies have identified a range of characteristics of HGFs, such as their innovation behaviour or firm size. However, they struggle with low explanatory power (Coad et al., 2013). At the regional or generally more aggregate level of analysis, we can uncover different regularities which cannot be captured at the firm level. The regional perspective allows to study the relationship between HGF shares and structural relationships and is thus complementary to firm-level studies.

Second, we add to the literature on HGFs and firm dynamics by considering the regional industrial structure, which can be interpreted economically as differences in the industrial portfolio. These lead to differences in mobility and growth barriers at the regional level. Our results suggest that an industrial base with higher technology intensity and lower mobility barriers is associated with greater HGF shares. An industrial base with higher technology intensity (or lower structural mobility barriers) is associated with greater HGF shares. This suggests that cross-country and cross-regional comparisons of HGFs should consider explicitly aspects of industrial specialisation. Our results suggest that, contrary to one of the 'stylised facts' documented in surveys about the HGF literature (Henrekson \& Johansson, 2010; Coad et al., 2014), industrial structures seem to play a role in shaping HGF shares. 


\subsection{The regional level of analysis}

Firm growth takes place at the firm level, which is the level of analysis chosen by most studies. Yet the most important finding from a policy perspective is the importance of HGFs for regional job growth, which is more pronounced than the contribution of small firms to job growth. In addition to the policy perspective, a regional analysis can be justified based on economic reasoning. Even though the firm-level literature of HGFs has identified important stylised facts associated with HGFs (Henrekson \& Johansson, 2010; Coad et al., 2014), microlevel studies struggle to find statistically significant determinants of fast firm growth due to heterogeneous growth processes. This is due to the high heterogeneity in firm behaviour (e.g., the seemingly erratic growth processes of small firms or the large degree of freedom of firm behaviour in oligopolistic markets). We argue that a change in the level of analysis can be fruitful.

The argument for a regional perspective hinges on market mechanisms. Market mechanisms are not coordinated at the firm, but at the market level but affect individual firm performance. This is akin to self-organisational dynamics emphasised in the evolutionary literature (e.g., Dosi et al., 2016 for a recent exploration), which emphasises that the outcomes of a system cannot be predicted from its single components. Aggregate outcomes (here: the regional HGF shares) can thus be considered emergent properties stemming from far-from-equilibrium interactions between economic entities, selection and heterogeneous learning (Frenken \& Boschma, 2007; Dosi, 2007).

The empirical Industrial Organization literature finds that market coordination differs across industries according to their structural characteristics. From an evolutionary perspective, the HGF shares at the regional level could be interpreted as an emergent property of the competitive interaction across industries (Dosi et al., 2016). This occurs at the regional level, is 
shaped by regional industrial structures and is largely unrelated to a representative or average firm.

Differences in statistical regularities between the firm and the regional level are therefore reflected in differences in persistence of growth (Dosi, 2007). Applying the definition of HGFs by the OECD-Eurostat ${ }^{1}, 2.7 \%$ of the entire firm population can be classified as HGFs, out of which only $3.9 \%$ are able to repeat their HGF status in two successive periods. Hence, only $0.11 \%$ of the entire population are repeatedly classified as HGFs (see section 3.2 for a discussion of the HGF definition). Existing studies find that high firm growth is not persistent over time (Daunfeldt \& Halvarsson, 2015; Bianchini et al., 2017), suggesting that most HGFs are "one-hitwonders".

HGF shares at the regional level display more persistence. A simple autoregressive OLS regression using information on NUTS-3 regions in Austria shows that the lagged HGF share explains $18 \%$ of the variance of HGF shares. The $\beta$-coefficient points at medium levels of autocorrelation ( $\beta$ : 0.40, p-value: 0.075, regionally clustered standard errors). Hence, the negligible autocorrelation of HGF status at the firm level turns into a more persistent pattern at the regional level. This suggests that regional HGF shares are rather unrelated to the persistence of being an HGF at the firm level. We therefore include the persistence of HGF at the firm level as a control variable, which is assumed to be unrelated with the regional HGF share.

\subsection{Structural determinants of HGF shares}

Both technological and market characteristics shape the interaction between firms, which in turn determines the regional HGF share. We explore how regional economic portfolio structures affect HGF shares. Thus, our approach is in contrast to a stylised fact in the literature

\footnotetext{
${ }^{1}$ HGFs are firms with an annualised growth rate of more than $20 \%$ over a three-year period and more than 10 employees at the beginning of the period (OECD and Eurostat, 2007).
} 
on HGFs. The surveys by Henrekson \& Johansson (2010) and Coad et al. (2014) state that there is no clustering of HGFs in certain industries. If there were no systemic differences in HGF shares across industries, then the regional industrial composition should not affect the share of HGFs.

This view conflicts with the common knowledge that underpins the standard Industrial Organization literature (e.g., Belleflamme \& Peitz, 2015) and models of evolutionary competition that consider the effects of different knowledge structures and technological regimes (e.g., Breschi et al., 2000). These literatures emphasize that differences between industries in sunk costs, innovation regimes and specificities of the production and distribution processes determine industry outcomes such as concentration or firm turnover (entry and exit).

This leads to the question of whether structural differences help explain differences in the shares of HGFs. A starting point for this discussion is the distribution of firm growth rates across regions. It is established that if firm growth rates are measured in log differences, their distribution follows a Laplace or Exponential Power distribution with heavy tails (Stanley et al., 1996; Bottazzi \& Secchi, 2006). The moments of this distribution differ across countries (e.g., Bravo-Biosca, 2010; Bravo-Biosca et al., 2016). This has been supported empirically by Hölzl (2011), who finds that fixed country effects explain approximately $23 \%$ of the observed variance of HGF shares across eleven countries, while fixed sector effects explain circa 35\%. Duschl et al. (2015) and Duschl (2016) study regional firm-growth distributions in Germany and document significant inter-regional heterogeneity that is linked to agglomeration effects. We follow this research and expect that differences in HGF shares are related to regional economic structures. 


\section{Hypotheses}

In the regional context, growth opportunities emerge through spillovers via industrial linkages between geographically bounded firms (e.g., Frenken et al., 2007). Thus, the industrial portfolio is likely to affect both firm dynamics and growth. Marshall's cluster theory (1890) states that the concentration of an industry in a region supports linkages between firms, leading to labour market pooling and specialised suppliers, which contributes to a region's economic performance. Porter (1998) suggests that the interplay of competition and industrial variety drives regional economic performance. Jacobs (1969) argues that the proximity of firms from different industries affects how well knowledge travels among firms, thereby facilitating innovation and growth.

Frenken et al. (2007) proposed entropy measures of the industrial portfolio which capture specialisation and localisation externalities. They measure specialisation by (i) the variety within related sectors and (ii) between sectors (i.e., unrelated variety), reflecting a diversified industrial portfolio. Empirical results for the Netherlands show that specialisation fosters employment growth, while a region's economic stability is promoted by greater levels of between-sector diversification. Duschl et al. (2015) used these entropy measures in an analysis of regional firm growth patterns in Germany. Their results show that firm-level turbulence is higher in regions with a higher aggregate growth performance, a highly qualified workforce and more unrelated variety in the industrial portfolio. Firms' growth prospects were inter alia found to be dampened by the agglomeration of own industry employment.

The industrial portfolio per se is related to sunk costs. These have been found to reduce reallocation dynamics and are negatively associated with HGF shares (Hölzl, 2015). Sunk costs act as mobility barriers by increasing exit costs. Hence, regions with a larger share of industries with high mobility barriers should display lower HGF shares. 
Hypothesis I: The share of high-growth firms is positively associated with variety indicators (measuring related and unrelated variety) and negatively associated with mobility barriers.

Firm formation has been causally linked to the presence of HGFs. It is thought that the same reallocation processes that drive entry and exit dynamics shape HGFs. Evidence shows that HGFs tend to be small and young - even though a subset of HGFs is large and old (Coad et al., 2014). The likelihood of observing more HGFs should therefore be greater in regions with more small and young firms. A higher entry rate should lead to an increase in the share of potential HGFs. A higher share of HGFs should be associated with a larger number of exits, especially if markets have fixed carrying capacities.

Either process is moderated by economic growth, which reduces selection pressures and is positively correlated with firm entry and negatively correlated with exit. Nevertheless, there is considerable evidence of a positive correlation of entry and exit rates at the industry level due to entry and exit barriers. This suggests that differences in entry and exit rates and HGF shares across regions after controlling for economic growth should reflect economic reallocation processes. For this reason, entry and exit rates are often seen as indicators of economic reallocation processes that enable structural change and technological re-orientation.

Hypothesis II: Entry and exit rates are positively associated with the share of high-growth firms (after controlling for economic growth). 
HGFs are a phenomenon of seized business opportunities. While these are abundant in times of high economic growth, a region's technology base may pose an additional aspect that is conducive to firm growth. Technology may shape both the number and size of business opportunities (Henrekson \& Johansson, 2010; Coad et al., 2014).

We draw on recent research on technological change and focus on information and communication technologies (ICT). Investments into ICT capital and skills are thought to generate spillovers and have been linked to productivity growth (Corrado et al., 2017). These processes are likely to occur at the regional level. Hence, regions with higher ICT intensities are likely to generate more spillovers and growth opportunities. This should again be linked to higher HGF shares.

Hypothesis III: Regions that feature an industrial structure with higher ICT intensity have a higher share of high-growth firms (after controlling for economic growth).

\section{Empirical methodology}

\subsection{Data}

We implement regression analysis to explore the role regional economic structures play for HGF shares. The data on HGF shares are based on Austrian Social Security data. This dataset contains information on all employers and the number of employees in the private sector in Austria. $^{2}$ Self-employed and public-sector workers are not covered. The data rely on social security numbers (firms) and contain the number of employees and the industry affiliation (ÖNACE Rev. 2, 3-digits). The 'Nomenclature of Territorial Units for Statistics' (NUTS), a European geo-code standard for referencing subdivisions of countries, is used to cover the

\footnotetext{
2 The data covers the NACE Rev. 2 sectors A to N.
} 
regional dimension. NUTS-3 divides Austria into 35 administrative districts. This allows to construct detailed regional indicators of the structure of the industrial portfolio. The dataset starts in 1974, but we restrict the sample to the period from 1995 through 2012 to maintain data comparability. Changes in the sector classifications and coverage make it difficult to use data before 1995. We construct a data set that reports yearly employment stocks for all private sector firms with at least one employee.

There are advantages of using administrative data compared to a survey-based analysis. This mainly concerns the data quality. The number of employees is a figure reported to the social security authority and not based on recall information, as it is in many surveys. The dataset fully covers the Austrian private sector. It is important to note that entry and exit are measured as the hiring of the first employee and firing of the last employee. ${ }^{3}$

A disadvantage of these data is that they do not provide information on whether entities are enterprises or establishments. The anonymous firm identifiers in the social security files are administrative accounts. It is left at the discretion of the firm whether it chooses to report at the enterprise or the establishment level. Hence, a series of plausibility checks has been used to ensure that business units are properly defined. Most observations are small firms, which are likely to be at the enterprise level, because having one account reduces administrative burdens when reporting social security contributions.

\footnotetext{
${ }^{3}$ Entry is defined as the hire of the first employee and not the establishment of the firm. This may be a drawback, but the HGF definition used only considers firms with more than 10 employees, which is why the deviation of the establishment year from the hiring date should not affect HGF shares. Also, firms that first exit and then re-enter are not recorded as exit and entry, because the social security numbers are kept on record, which allows us to distinguish "true" entries from re-entries.
} 


\subsection{High-growth firm shares}

We use the OECD-Eurostat definition of HGFs, which defines HGFs as firms with at least ten employees in the start-year and annualised employment growth exceeding $20 \%$ during a 3 year period (Eurostat-OECD, 2007). ${ }^{4}$ The time dimension of the definition allows to smooth yearly fluctuations. Hence, we compute the indicators for non-overlapping three-year periods, i.e. 1995-1997, 1998-2000, 2001-2003, 2004-2006, 2007-2009 and 2010-2012. This provides us with a pooled sample with a total of 210 observations for six periods. The growth indicator is defined as:

$$
\left(E_{i, t} / E_{i, t-3}\right)^{1 / 3}-1 \geq 0.2 \quad \text { if } E_{i, t-3} \geq 10,
$$

where $E_{i, t}$ is employment for firm i at time t. Thus, we do not consider firms with fewer than ten employees in the respective base year (t-3), nor entry-exit dynamics in the definition of HGFs. The measurement of HGFs is not uncontroversial (Coad et al. 2014). Some research (e.g., Daunfeldt et al, 2015) has criticised the Eurostat-OECD definition on the basis that it excludes many firms. Other researchers questioned the usefulness of relative growth rates, because relative growth measures favour smaller firms.

After defining HGFs at the firm level, we compute regional HGF shares as the number of HGFs in a region over the number of firms with more than 10 employees at the beginning of the period in the region.

\subsection{Distributions of firm growth rates across regions}

The Austrian growth rate distribution is characterised by a comparatively low number of high-growth and high-decline firms, and a relatively large fraction of stable firms. To provide

\footnotetext{
${ }^{4}$ In 2014 EUROSTAT changed the growth criterion used to define HGFs from $20 \%$ per year over three years, to $10 \%$ per year over three years. There does not seem to be any published rationale for this change (Anyadike-Danes et al. 2018). EUROSTAT still reports data for the 20\% criterion.
} 
some evidence on the regional heterogeneity of HGFs, we perform t-tests and an analysis of variance (ANOVA) to examine whether HGF shares differ across regions.

The HGF share of most regions does not differ in a statistically significant way from the other regions in the sample. Only for four out of 35 regions, about $11 \%$ of the sample we reject the null hypothesis of no statistical difference in means from the rest of the sample at the $1 \%$ level. At 5\% significance, we find that eleven regions have HGF shares that are statistically different.

An ANOVA of HGF shares at the regional level with region and time fixed effects explains around $50.8 \%$ of the variance of HGF shares across regions. Fixed regional effects account for $46.3 \%$ of the total variance. This indicates heterogeneity in HGF shares across regions, which provides additional motivation for our regional analysis.

The distributions of growth rates are remarkably stable over time. If we consider the share of stable firms (firms with an annualised growth rate between $-5 \%$ and $5 \%$ over a three-year period) we obtain a highly significant correlation coefficient of 0.62 for two non-overlapping periods across regions. The autocorrelation coefficient for the HGF share is 0.39 and statistically significant. There is clearly a difference between the persistence of high growth at the firm level, which is very low, and the persistence of the share of HGFs at the regional level. 5

Figure 1 illustrates the share of HGFs in Austria's NUTS-3 regions over time. It shows that HGF shares vary across regions. While in some periods very few regions showed no HGF at all, the maximum share of HGFs is $6.2 \%$; the mean HGF share across all regions and periods is 2.7\%. More urban regions seem to exhibit higher HGF shares (descriptive statistics are in the annex table A1).

\footnotetext{
${ }^{5} \mathrm{An}$ average of $3.9 \%$ of HGFs in our sample are classified as HGFs in two consecutive three-year periods. Coad et al. (2014) stress that high growth is not persistent over time, which is one of the seven stylised facts identified by the empirical literature.
} 
Figure 1: Regional distribution of HGF shares at the NUTS3 level
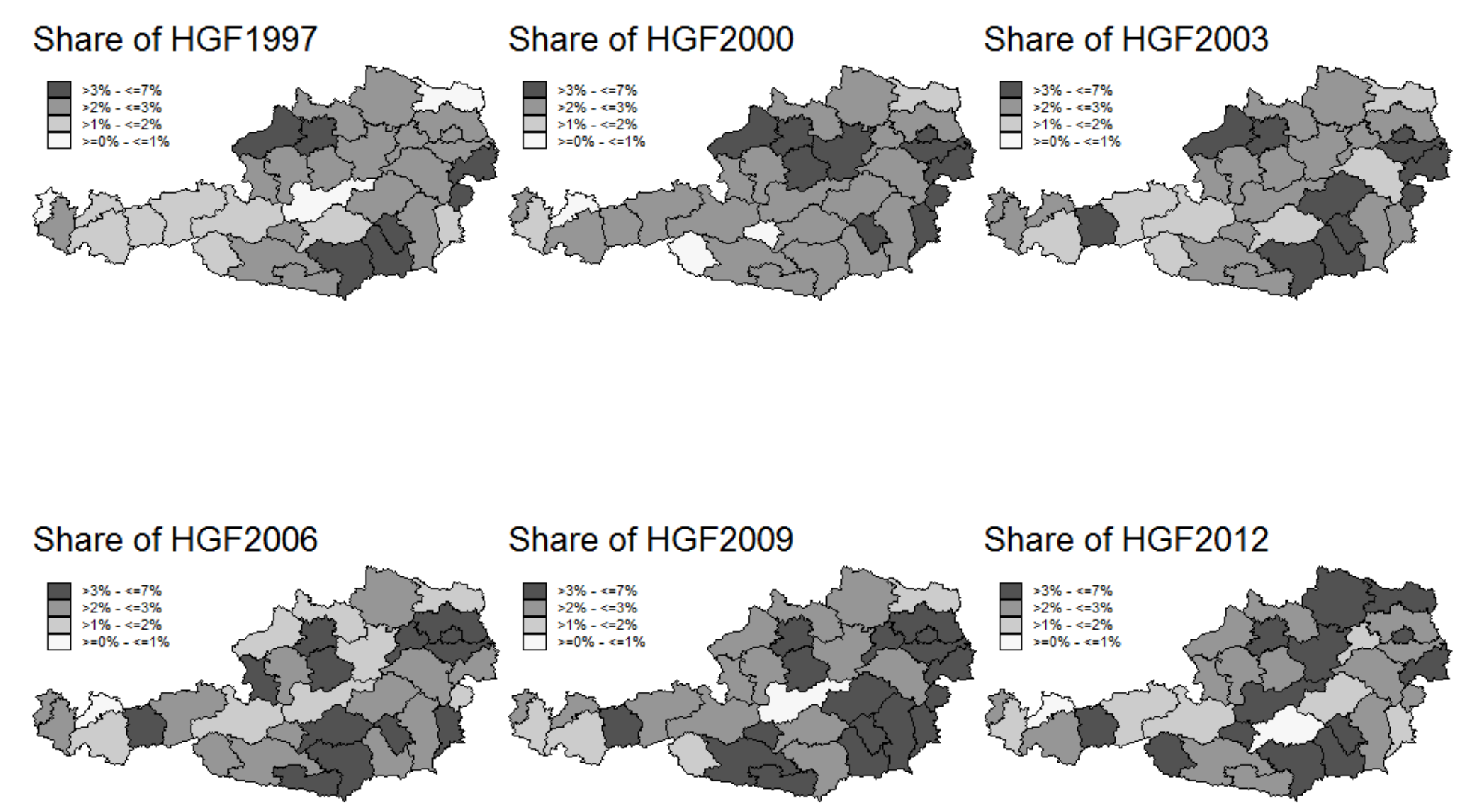

Source: Data from social-security files; shape file of visualisation by Statistics Austria; own calculations. 


\subsection{Explanatory Variables}

We explain the share of HGFs by structural characteristics, controlling for the firmlevel persistence and regional growth differences. The econometric set up is the following:

$$
H G F_{r, t}=\alpha+\boldsymbol{\beta} \boldsymbol{X}_{r, t}+\boldsymbol{\gamma} \boldsymbol{C}_{\boldsymbol{r}, \boldsymbol{t}}+\varepsilon_{\mathrm{r}, \mathrm{t}},
$$

where HGF denotes the HGF share for region $r$ and the three-year period $t$. $\boldsymbol{\beta}$ are the regression coefficients associated with the set of explanatory variables $\mathbf{X}_{\mathbf{r}, \mathbf{t}}$ that are used to test the hypotheses outlined in section 2. $\gamma$ denotes the regression coefficients associated with the set of control variables $C_{r, t}$ and $\varepsilon$ is an error term.

To test Hypothesis I, we use two variables that capture the relatedness and diversity of the local industrial portfolio. These also measure the technological proximity of sectors within Austrian regions. The third indicator captures differences in the sunk cost intensity of the industrial structure within regions.

The indicator of related variety (RV) measures the potential of spillovers between related industries but can also be interpreted in terms of the specialisation of the industrial base. It has been argued that knowledge spillovers rather occur between industries which are technologically related than between unrelated industries (Frenken, Van Oort, \& Verburg, 2007). A higher related variety in a region should positively contribute to the emergence of HGFs if they depend on knowledge spillovers from related industries (i.e., clusters). In measuring related variety, we follow Frenken, Van Oort, and Verburg (2007). Due to data availability we use the NACE-3-digit instead of the NACE-5-digit industry definition to construct the indicators: 


$$
R V_{s, r}=\sum_{s=1}^{S} \frac{E_{s, r}}{E_{r}} \mathrm{H}_{\mathrm{s}, \mathrm{r}}
$$

where $H_{s, r}=\sum_{i=1}^{I} \frac{E_{i, s, r}}{E_{s, r}} \log _{2}\left(\frac{E_{s, r}}{E_{i, s, r}}\right)$ and $\mathrm{i}$ is the number of 3-digit industries within each 2-digit sector $s . \mathrm{E}_{\mathrm{i}, \mathrm{s}, \mathrm{r}}$ denotes employment in NACE 3-digit industry $i$ belonging to sector $s$ in region $r$, so that the regional employment share of industry $i$ in sector $\mathrm{s}$ is given by $E_{i, s, r} / E_{s, r}$. Related variety in production in region $r$ is thus measured by the weighted sum of the entropy of employment shares across the 3-digit industries within each 2-digit sector.

Unrelated variety (UV) measures the diversity of the industrial portfolio at the NACE 2-digit level. It is defined as measured by the Shannon entropy over the region's employment shares in the 2-digit sectors (Frenken et al., 2007):

$$
U V_{r}=\sum_{S=1}^{S} \frac{E_{S, r}}{E_{r}} \log _{2}\left(\frac{E_{r}}{E_{S, r}}\right)
$$

where $S$ is the total number of 2-digit sectors, and $\mathrm{E}_{\mathrm{s}, \mathrm{r}}$ is employment in NACE 2-digit sector $s$ in region $r$. The share of 2-digit sector $\mathrm{s}$ in total regional employment is given by $E_{s, r} / E_{r}$. The coefficient on UV should be positive if HGF presence is associated with the variety of the regional industrial portfolio.

The next variable is a regional interpretation of excess labour turnover, EXLT, which, in its original form, was defined as the sum of job creation and destruction rates less the absolute value of the net employment growth rate (Davis et al. 1996). We use a regionally weighted expression of the indicator. Excess labour turnover is calculated at the national industry (2-digit) level to smooth firm-specific effects that emerge at the regional level due to 
the small number of observations in many industries. The indicator is aggregated to the regional level using industry employment shares at the region level:

$$
\operatorname{EXLT}_{r, t}=\sum_{i} \frac{0.5 *\left(E_{r, i, t}+E_{r, i, t-1}\right)}{0.5 *\left(E_{r, t}+E_{r, t-1}\right)} \frac{\left(J C_{i, t}+J D_{i, t}-\left|J C_{i, t}-J D_{i, t}\right|\right)}{0.5 *\left(E_{i, t}+E_{i, t-1}\right)},
$$

where $\frac{0.5 *\left(E_{r, i, t}+E_{r, i, t-1}\right)}{0.5 *\left(E_{r, t}+E_{r, t-1}\right)}$ is the average employment share of industry $i$ in region $r$ in time $t-1$ and $t$. These shares are used as weights to construct the regional excess labour turnover indicator as a regional variable. The second expression is excess labour turnover measured at the industry and national level, where $J C_{r, i, t}$ is job creation, $J D_{r, i, t}$ is job destruction (as a positive number), and $E_{r, i, t}$ and $E_{r, i, t-l}$ denote the employment levels for the periods $t$ and $t-1$ of industry $i$ and region $r$. The use of this indicator is motivated by the fact that $E X L T_{r, t}$ should be a (general) structural indicator reflecting mobility barriers (Hölzl, 2015).

EXLT captures the (average) excessive turnover of employment that is not related to changes in the level of employment. The measure captures the "excess" reallocation over and above that needed to accommodate net employment growth. Hölzl (2015) argues that EXLT is not only a labour reallocation indicator, but also a proxy for mobility barriers related to intangible organisational capital. EXLT, a measure of non-capital costs, proxies the sunk costs of routines, labour-embodied product-specific know-how and the "replacement cost" of the skilled workforce. The motivation to use EXLT as an indicator of mobility barriers derives from labour economics and transaction cost theory. A lower value of EXLT indicates a higher cost of labour turnover for firms due to more firm-specific human capital. Thus, a lower value of EXLT signals higher mobility barriers due to intangible organisational capital. 
It is measured at the industry level and then aggregated, therefore regions with a higher share of mobility barrier industries will have a lower EXLT and vice versa.

To test Hypothesis II, we use explanatory variables capturing firm entry and exit.

We next define regional entry rates and exit rates. The entry rate is the number of new firms relative to the total number of firms, and the exit rate is the number of exits relative to the total number of firms. Both rates are calculated as averages of the yearly entry and exit rates over the respective period.

We capture the digitalisation content of regional industry structures by a recently proposed OECD taxonomy of digital intensity. The taxonomy uses a set of indicators to classify 36 ISIC Rev. 4 sectors over the period 2001-2015. The indicator measures firms' investments in digital assets, the use of digital technologies in production, human capital or the use of ICT. ${ }^{6}$ The taxonomy distinguishes four distinct sector groups: industries with low, medium-low, medium-high and high digital intensity. This indicator has been found to consistently capture a multitude of digital aspects (Calvino et al., 2018). Using the employment statistics, we construct regional employment shares for each of the four digital intensity industry groups.

The control variables $\left(C_{r, t}\right)$ are regional employment growth, persistence of HGFs, population density and time effects. Regional employment growth should control for demand dynamics. Hölzl (2016) found that HGF shares are sensitive to the output gap. A negative output gap is associated with a lower HGF share, while a positive output gap is associated with larger HGF shares. We use regional employment growth over the same three-year

\footnotetext{
${ }^{6}$ The indicators used comprise the share of ICT tangible and intangible (i.e. software) investment, the share of purchases of intermediate ICT goods and services, the stock of robots per hundreds of employees, the share of ICT specialists in total employment and the share of turnover from online sales.
} 
periods as the HGF shares to capture differences in regional local economic growth, as time dummies are used to control for aggregate demand and supply shocks. ${ }^{7}$ We expect a positive relationship between regional employment growth and HGF shares. ${ }^{8}$

The persistence of HGFs is used to study a possible link between HGF persistence at the firm level and regional HGF shares. This indicator measures the share of HGFs that was able to repeat their growth performance in two consecutive three-year periods ( $\mathrm{t}$ and $\mathrm{t}-1)$. It is calculated from the social security database.

We use the regional population density to control for region size. This indicator is based on census data for 2001 and 2011, and is expressed in millions to make the coefficients comparable.

\subsection{Estimation strategy}

We implement a series of regressions to test the hypotheses. The main specifications use OLS regressions with standard errors clustered at the regional level. Cognisant of the limitations of cross-sectional methods, we use the panel structure to implement a lagged dependent variable regression, addressing concerns about endogeneity and gauging the validity of the results. Eventually, we use a specification explaining the hypothetical share of HGFs given the composition of the regional economy, thereby considering a quasi-counterfactual to make further strides towards establishing a causal relationship (see Table 1).

\footnotetext{
7 We also used employment growth based on regional statistics. This covers the whole economy. Differences are negligible.

8 However, Bos \& Stam (2013) provide evidence that the presence of HGFs is associated with subsequent industry employment growth.
} 
The baseline specification (1) considers the structural variables RV, UV, mobility barriers and firm turnover, also controlling for time effects, regional growth and population density (see Online Annex for additional robustness checks). Specifications (2) to (5) include the digitalisation intensity of the industry structure, which draws on the ICT taxonomy proposed by Calvino et al. (2018).

The next two specifications present robustness checks. Specification (6) uses the panel structure and reports the results of a Blundell-Bond lagged dependent variable regression. This robustness check introduces a dynamic perspective, which allows to interpret the results in a more causal way. Hence, we link changes in HGF shares to changes of the explanatory variables. The lagged dependent variable and both the structural and cyclical set of indicators are specified as GMM-style instruments (i.e., the lagged share of HGFs, unrelated variety, related variety, employment growth, excess labour market volatility and the entry and the exit rate). This addresses the concern that neither the variety indicators nor labour market and entry-exit dynamics can be taken as strictly exogenous to the share of HGFs. In addition, the population density and time effects are used as IV-style instruments. The chosen estimation passes the post-estimation test. The $\mathrm{AR}(1)$ test is highly significant (p-value: 0.000 ) and suggests the use of a lagged dependent model. The differenced residuals do not exhibit significant $\mathrm{AR}(2)$ behaviour (p-value: 0.178). The Sargan-Hansen test is statistically insignificant ( $p$-value: 0.123 ).

The final specification (8) uses another dependent variable (STR), which captures the effect of the composition of the regional economy. We construct a regional HGF share that considers only the regional sector composition. We draw on a rather aggregated sector 
classification, which is also used in the regional economic accounts by Statistics Austria and Eurostat: Mining (section B in NACE Rev. 2), Manufacturing and Energy $(\mathrm{C}+\mathrm{D}+\mathrm{E})$, Construction (F), Distribution, Hotel \& Restaurants, Transport, Storage and Communications $(\mathrm{G}+\mathrm{H}+\mathrm{I})$ and Financial Intermediation, Real Estate, Renting and Business Activities $(\mathrm{J}+\mathrm{K})$. The number of firms with more than ten employees is used to calculate sector shares for each region in each time period. We use the aggregated sectoral HGF shares and the sector shares to calculate a hypothetical HGF share for each region and period. Comparing the results using this hypothetical HGF share with results using the observed HGF share allows to discuss the economic importance of our hypotheses in a more precise manner. 
Table 1: Regression results

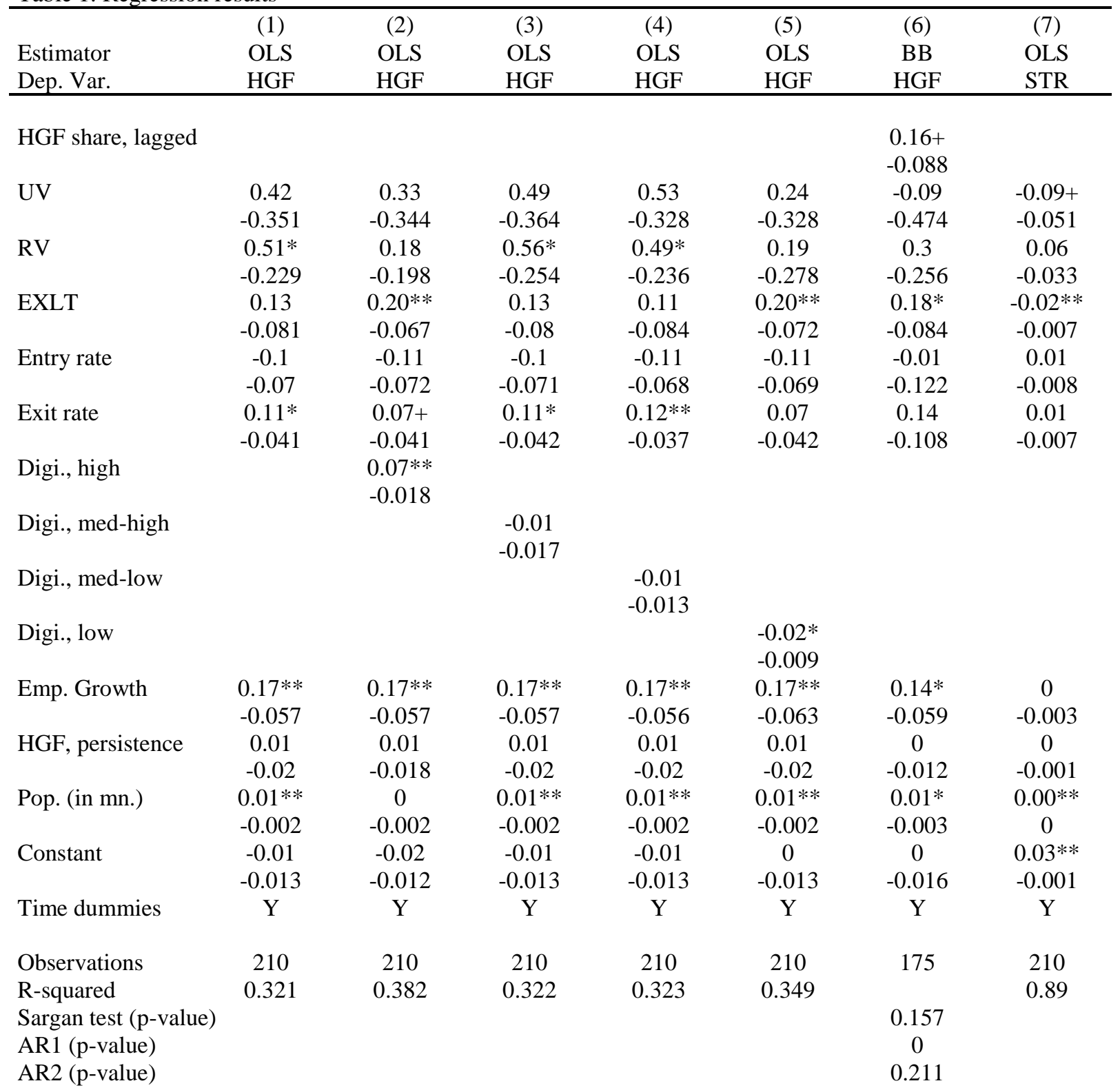

Note: This table shows the regression results explaining regional HGF shares; STR denotes a hypothetical HGF share based on the regional industrial structures. OLS denotes ordinary least squares reporting s.e. clustered at the NUTS-3 level in parentheses. BB denotes a Blundell-Bond lagged dependant variable estimator. Significance levels: $* * \mathrm{p}<0.01, * \mathrm{p}<0.05,+\mathrm{p}<0.1$. 


\section{Regression results and discussion}

We first explore Hypothesis I, which states that the share of HGFs is positively related to the regional industrial variety, measured by two unrelated (UV) and related variety (RV), and is negatively related to mobility barriers (EXLT).

We obtain positive yet insignificant results for UV in most specifications. The dynamics of HGF shares are therefore not statistically associated with the unrelated variety of the regional industrial portfolio. This result stands in contrast with the evidence for Germany provided by Duschl et al. (2015), who found that the tails of firm-growth distributions were weakly associated with unrelated variety. It also stands in contrast with the findings by Firgo and Mayerhofer (2017), who linked employment growth in Austria to both related and unrelated variety, finding a stronger effect for the latter.

The coefficients for related variety (RV) are positive and significant in specification (1), (3) and (4). Related variety is therefore positively, but weakly associated with the HGF share. This can be interpreted as the effect of spillovers from firms in similar industries. It is a measure of industry-level specialisation and technological complementarities of the activities within a region (Duschl et al., 2015). This is broadly in line with Frenken et al. (2007), who report employment growth enhancing effects of related variety, which are likely to be related to higher HGF shares.

The coefficients of related variety turn insignificant when regional fixed-effects are considered (6). This is due to the time persistence of structural factors (Frenken et al., 2007), which are absorbed by the fixed effects in the observation period. Fixed-effects estimators are inappropriate for analysing structural aspects that change very slowly over time. 
The third structural indicator analysed is EXLT, a measure of mobility barriers related to the organisation of production. A higher value of the EXLT indicates lower mobility barriers. Hence, a negative relationship between mobility barriers and HGFs is indicated by a positive regression coefficient. We obtain statistically insignificant results in the regression (1), our main specification. However, the indicator turns significant when including the high (2) and low (5) digitalisation intensity of the industry structure as well as in the lagged dynamic variable estimator (6). Hence, mobility barriers are found to be negatively yet weakly associated with HGF shares. The HGF share in a region is higher the lower the importance of high mobility barriers industries is. This supports the findings of Hölzl (2015) who argued that mobility barriers (intangible sunk costs) affect the growth rate distribution and the HGF share.

Hypothesis II argues that entry rates and exit rates are positively associated with the regional share of HGFs. The coefficients for firm entry are negative and statistically insignificant throughout all specifications. This puts policies that focus on firm entry to generate more HGFs and thus successful firms into question. However, to draw clear conclusions for policy makers, more in-depth analyses about the underlying mechanisms are needed.

The results for exit rates are positive and statistically significant in specification (1), (3) and (4). This may indicate replacement dynamics, in which HGFs grow their market shares, through which they increase selection pressures, which again leads to firm exit. Controlling for the panel structure renders the coefficients statistically insignificant, which suggests that exit (and entry) patterns are related to time-invariant, unobserved regional 
characteristics, such as structural barriers to entry. If firm exit and HGFs are simultaneous phenomena, the promotion of HGFs could accelerate the renewal of the firm base (Coad et al., 2014) 9

Hypothesis III states that higher ICT intensities are positively associated with more HGFs. The regressions (2) to (5) use the ICT taxonomy proposed by Calvino et al. (2018) and draw on the baseline specification (1). A greater sector share of highly ICT-intensive industries is found to be positively associated with regional HGF shares. A greater share of industries with low ICT intensity is negatively associated with HGF shares. Medium digitalisation intensity shares are found to be statistically insignificant and not to be associated with HGF shares. If these digitalisation indicators are interpreted as proxies for technological entrepreneurial opportunities, the results suggest that technological opportunities foster high firm growth.

The control variables perform as expected. The regional HGF shares are unrelated to the persistence of HGF at the firm level. The coefficients are close to nil and statistically insignificant. This suggests that the persistence of regional HGF shares is primarily an outcome of market interaction, and not of HGFs repeating their growth performance. This supports the regional level of analysis. The coefficients for population density and the (unreported) time effects are statistically significant.

The coefficients for regional employment growth are positive and statistically significant. This variable is included to identify the structural relationships of interest. Conceptually and statistically it is difficult - perhaps impossible - to establish causality from

\footnotetext{
${ }^{9}$ When time dummies were excluded, the entry rate turned significant, indicating that economy-wide cyclicality can induce an association between the entry rate and the HGF share which is otherwise captured by the time effects (see Online Annex).
} 
economic growth to HGFs, or vice versa. HGF shares are more pronounced if firms can exploit the opportunities provided by growing regional demand. The relationship is found to be contemporaneous. ${ }^{10}$ Controlling for regional (employment) growth reveals a statistically significant relationship with HGF in each specification. This is after controlling for time effects capturing demand effects that are uniform across regions. The unreported time dummies are also statistically significant.

The explanatory power of the estimated models is substantially higher than what is usually reported at the firm level (Coad et al., 2014). This also supports that spatial indicators capture structural characteristics of the regional market environment which emerge at a more aggregated level. The $\mathrm{R}^{2}$ of the estimated specifications is greater than 0.32 . This is due to the aggregation of heterogeneous firm data into growth brackets, or distributional moments, which, by definition, reduces heterogeneity.

The results are not driven by differences in the institutional and regulatory setting. Even if Austria is a federal country, product and labour market regulations and taxation are almost uniform across Austrian regions and Länder (e.g., Pitlik, 2014). The most relevant subsidy schemes are set at the national level and merely matched by regional agencies (e.g., Kaufmann \& Tödtling, 2002). Hence, regulatory and taxation differences are hardly relevant for this study. Yet regional industrial structures are still heterogeneous, allowing for an analysis of the share of HGFs across regions.

\footnotetext{
10 See Online Annex.
} 


\subsection{Robustness checks}

To test the robustness of our baseline specification, we implement a lagged dependent variable estimation (6). Only the indicators employment growth and sunk costs are statistically significant. The coefficient of $y_{t-1}$ indicates a weakly significant and low degree of autocorrelation ( $\beta$ : 0.16 ; p-value: 0.065$)$, which is substantially below the unconditional autoregressive term of the $\operatorname{OLS}-\mathrm{AR}(1)$ regression $(\beta: 0.40 ; \mathrm{p}$-value: 0.075$)$. The autoregressive nature of the HGF shares is partly absorbed by the fixed effects, also rendering the coefficients of the structural variables largely insignificant.

In addition, it could be argued that the HGF shares at the regional level are predominantly driven by the regional sector composition. Hence, we compute the regional firm weights for broad industries, and calculate hypothetical regional HGF shares (STR) using aggregate HGF shares. We use these hypothetical HGF shares to explore the extent to which the estimated coefficients hinge on a broad sector composition rather than regional specificities. The results (specification 7) show that almost all coefficients are statistically insignificant. This supports the argument that regional HGF shares are rooted in the local interaction of firms within and across sectors and are not the mere result of the regional sector composition per se.

\subsection{Economic impact}

The previous discussion has taken a conceptual stance. Using the estimated coefficients from our baseline specification (1), we compute the impact of statistically significant variables on the regional HGF share. The regional HGF share has a mean of $2.7 \%$ 
and a standard deviation of one percent. Increasing the indicators related variety, the exit rate and mobility barriers (EXLT) by one standard deviation leads to an increase in the HGF share of $0.2 \%$ in either case, or approximately a fifth of the standard deviation of the regional HGF share. Notably, a higher EXLT indicates a lower degree of mobility barriers. Increasing employment growth by one standard deviation leads to an increase of the HGF share by approximately $0.3 \%$ or $28 \%$ of the standard deviation of the regional HGF share. We use the coefficients obtained by regression (2) and (5) to compute the economic impact of the digitalisation intensity on HGF shares. Increasing the share of highly ICT-intensive industries by one standard deviation would induce $0.4 \%$ more HGFs, which corresponds to $37 \%$ of the standard deviation of HGF shares. Decreasing the share of industries with low ICT intensity would increase the HGF share by $0.2 \%$ ( $19 \%$ of the standard deviation).

\section{Summary and conclusions}

This paper studied the phenomenon of high-growth firms (HGFs) at the regional NUTS-3 level. We used Austrian data on all private sector firms for three-year periods between 1995 and 2012 and applied the definition of HGFs by the Eurostat-OECD Manual on Business Demography Statistics. Even though firm-level evidence on the characteristics of HGFs has revealed a range of regularities, a regional, more aggregate perspective allows capturing the determinants that shape the opportunities and constraints of HGFs that are not detectable at the firm level. Although Austria is organised as a federal state, the uncovered effects are very unlikely to be driven by regulatory differences, since taxes and labour and product market regulations are largely set at the national level. 
We provide evidence that regional industrial specialisation patterns and industrial structures affect HGF shares. More precisely, the regression results indicate that HGFs are more prevalent in regions with higher specialised industrial portfolio (related variety) rather than in regions with a more diversified industrial portfolio. Higher shares of industries with high mobility barriers tend to be associated with lower HGF shares..An larger shares of industries with high digitalisation intensities are related to a higher share of HGFs.

These findings support results for Germany by Duschl et al. (2015) who report that the technology base of a region positively affects firms' growth prospects. Yet, we only provide evidence for Austrian regions, which is why further studies are needed to confirm the general validity of our findings and to provide robust evidence on the link between regional firm growth dynamics and economic performance. In addition, Austria is a small, open and highly developed economy. The effect of regional characteristics and learning processes on HGF shares might differ in catching-up and developing economies. A second limitation concerns the industry level. We analysed the total private sector at the regional level. Even though we considered the ICT/digitalisation content, and in the robustness checks the composition of the regional economy in an aggregate analysis, the results might differ further across sectors. Also, this study explored the structural determinants of HGFs, which may be shaped by presently unobserved spatial factors such as unevenly distributed infrastructure or the regional knowledge base. These approaches are beyond the scope of this paper, however.

Nevertheless, we believe that our findings are relevant. The results indicate that robust relationships between HGF shares and possible determinants can be uncovered at a regional, more aggregate level of analysis. This is because outcomes of market processes are only 
revealed in a limited way by firm-level studies, but become more visible as emergent properties at the regional (national or even industry) level. The results also suggest that more attention should be paid to structural and demand-side determinants of HGFs, which may be central elements that help explain differences in HGF prevalence between regions and countries and differences in the impact of HGFs on aggregate economic outcomes.

Our results do not support the claim that economic dynamism and the emergence of HGFs are closely linked to firm entry (start-up) dynamics. In contrast, we uncover a (weak) link between HGFs and firm exit. This suggests that the relationship between HGF shares and entry and exit dynamics requires more attention in future research. But our findings suggest a link between digitalisation intensity and the associated technological and market opportunities and HGFs shares. This corroborates the idea that HGFs tend to be carriers of economic transformations, and that HGFs are more prevalent when economic structures offer novel technological and market opportunities. This suggests that technology diffusion policies can be an important ingredient in policies that aim at fostering the presence of HGFs in a region and to support structural transformations.

The finding that structural aspects play an important role as determinants of regional HGF shares limits the leverage of isolated policies in fostering HGFs. Structural characteristics such as a region's specialisation patterns change only slowly over time and are hardly affected by policy measures targeting a few potential high-growth firms. This suggests that policies that foster HGFs should be seen as one element in a broad portfolio of regional and structural policies, which take into account existing industrial structures, economic incentives and knowledge bases. 


\section{References}

Andrews, D., \& Cingano, F. (2014). Public policy and resource allocation: evidence from firms in OECD countries. Economic Policy, 29(78), 253-296.

Anyadike-Danes, M., Bjuggren, C., Dumont, M., Gottschalk, S., Hölzl, W., Johansson, D., Maliranta, M., Myrann, A., Nielsen, K., Zheng, G. (2018) An International Comparison of the Contribution to Job Creation by High-growth Firms, WIFO Working Paper No. 563.

Bartelsman, W., Haltiwanger, J., \& Scarpetta, S. (2013). Cross-country differences in productivity: The role of allocation and selection. American Economic Review, 103(1): $305-334$.

Belleflamme, P., \& Peitz, M. (2015). Industrial organization: markets and strategies. Cambridge University Press.

Bianchini, S., Bottazzi, G., \& Tamagni, F. (2017). What does (not) characterize persistent corporate high-growth?. Small Business Economics, 48(3), 633-656.

Birch, D. L. \& Medoff, J (1994): Gazelles. In: Solmon, L. C. und A. R. Levenson (eds): Labor Markets, employment policy and job creation. Boulder, CO: Westview und Birch, $159-167$.

Bos, J. W., \& Stam, E. (2013). Gazelles and industry growth: a study of young high-growth firms in The Netherlands. Industrial and Corporate Change, 23(1), 145-169.

Bottazzi, G., \& Secchi, A. (2006). Explaining the distribution of firm growth rates. The RAND Journal of Economics, 37(2), 235-256.

Breschi, S., Malerba, F., \& Orsenigo, L. (2000). Technological regimes and Schumpeterian patterns of innovation. Economic journal, 110(463), 388-410.

Bravo-Biosca, A. (2010). Firm growth dynamics across countries: Evidence from a new database. FORA-NESTA Working Paper.

Bravo-Biosca, A., Criscuolo, C., \& Menon, C. (2016). What drives the dynamics of business growth? Economic Policy, 31(88), 703-742.

Calvino, F., Criscuolo, C., Marcolin, L., Squicciarini, M. (2018): "A taxonomy of digital intensive sectors", OECD Science, Technology and Industry Working Papers, No. 2018/14. Available at: https://doi.org/10.1787/f404736a-en (accessed on 1 April 2019). 
Coad, A., Daunfeldt, S. O., Hölzl, W., Johansson, D., \& Nightingale, P. (2014). High-growth firms: introduction to the special section. Industrial and Corporate Change, 23(1), 91-112.

Coad, A., Frankish, J., Roberts, R. G., Storey, D. J. (2013). Growth paths and survival chances: An application of Gambler's Ruin theory. Journal of Business Venturing, 28(5), 615-632.

Corrado, Carol, Jonathan Haskel, and Cecilia Jona-Lasinio. (2017). Knowledge spillovers, ICT and productivity growth. Oxford Bulletin of Economics and Statistics, 79(4), 592-618.

Daunfeldt, S. O., \& Halvarsson, D. (2015). Are high-growth firms one-hit wonders? Evidence from Sweden. Small Business Economics, 44(2), 361-383.

Daunfeldt, S. O., Johansson, D., \& Halvarsson, D. (2015). Using the eurostat-OECD definition of high-growth firms: a cautionary note. Journal of Entrepreneurship and Public Policy, 4(1), 50-56.

Davis, S. J., Haltiwanger, J., \& Schuh, S. (1996). Small business and job creation: Dissecting the myth and reassessing the facts. Small Business Economics, 8(4), 297-315.

Dosi, G., Pereira, M.C. \& Virgillito, M. E. (2016) The footprint of evolutionary processes of learning and selection upon the statistical properties of industrial dynamics, Industrial and Corporate Change 26(2), 187-210.

Dosi, Giovanni (2007). "Statistical Regularities in the Evolution of industries. A guide trough some evidence and challenges for the theory”. In Malerba, F. and Brusoni, S. (Eds.) Perspectives on innovation, Cambridge University Press, pp. 153-186.

Duschl, M. (2016). Firm dynamics and regional resilience: an empirical evolutionary perspective. Industrial and Corporate Change, 25(5), 867-883.

Duschl, M., Scholl, T., Brenner, T., Luxen, D., \& Raschke, F. (2015). Industry-specific firm growth and agglomeration. Regional Studies, 49(11), 1822-1839.

Eurostat-OECD (2007). Eurostat-OECD Manual on business demography statistics. Office for Publications of the European Communities, Luxembourg.

Firgo, M., \& Mayerhofer, P. (2017). (Un) related variety and employment growth at the subregional level. Papers in Regional Science. 
Frenken, K., \& Boschma, R. A. (2007). A theoretical framework for evolutionary economic geography: industrial dynamics and urban growth as a branching process. Journal of Economic Geography, 7(5), 635-649.

Frenken, K., Van Oort, F., \& Verburg, T. (2007). Related variety, unrelated variety and regional economic growth. Regional Studies, 41(5), 685-697.

Henrekson, M., \& Johansson, D. (2010). Gazelles as job creators: a survey and interpretation of the evidence. Small Business Economics, 35(2), 227-244.

Hölzl, W. (2011). Unternehmenswachstum im internationalen Vergleich. WIFO Monatsberichte, 84(8), 557-567.

Hölzl, W. (2015). Sunk costs and the speed of market selection. Journal of Evolutionary Economics, 25(2), 323-344.

Hölzl, W. (2016). High growth firms in Europe. In European Commission, Science, Research and Innovation performance of the EU: A contribution to the open innovation, open science, open to the world agenda: 2016. Brussels: European Commission.

Jacobs, J. (1969). The economy of cities. New York, NY: Random House.

Kaufmann, A., \& Tödtling, F. (2002). How effective is innovation support for SMEs? An analysis of the region of Upper Austria. Technovation, 22(3), 147-159.

Marshall, A. (1890), Principles of Economics, London, Macmillan. Neffke, F., Henning, M., \& Boschma, R. (2011). How do regions diversify over time? Industry relatedness and the development of new growth paths in regions. Economic Geography, 87(3), 237-265.

Pitlik, H. (2014). Fiscal Federalism, Austrian Style: Fear of Competition. In: S. A. Lütgenau (Ed.), Fiscal Federalism and Fiscal Decentralisation in Europe. Comparative Case Studies on Spain, Austria, the United Kingdom and Italy. Foster Europe, Foundation for strong European Regions, Innsbruck, Wien, Bozen, 41-59.

Porter, M. E. (1998). Clusters and the new economics of competition. Harvard Business Review, 76(6), 77-90.

Shane, S. (2009). Why encouraging more people to become entrepreneurs is bad public policy. Small Business Economics, 33(2), 141-149. 
Stanley, M.H.R., Amaral, L.A.N., Buldyrev, S. V., Havlin, S., Leschhorn, H., Maass, P., Salinger, M.A., \& Stanley H.E. (1996). Scaling behaviour in the growth of companies, Nature, 379(6568), 804-806. 
ANNEX (FOR ONLINE PUBLICATION ONLY) 
All variables of interest are structural. Even if we do not find multicollinearity, there might be spurious interactions between these variables which we seek to uncover. Hence, we also implement regressions using the individual aspects separately including only time effects. This leads to the full specification.

Table B1: Robustness checks, determinants of high growth firm shares at the NUTS-3 level in Austria

\begin{tabular}{|c|c|c|c|c|c|c|c|c|}
\hline & (1) & (2) & (3) & (4) & (5) & (6) & (7) & (8) \\
\hline Estimator & OLS & OLS & OLS & OLS & OLS & OLS & OLS & $\mathrm{FE}$ \\
\hline Dep. Var. & HGF & HGF & HGF & HGF & HGF & HGF & HGF & HGF \\
\hline HGF share, lagged & & & & & & & & \\
\hline HGF, persistence & 0.01 & & & & & & & 0.00 \\
\hline UV & & $\begin{array}{c}0.38 \\
(0.343)\end{array}$ & & $\begin{array}{c}0.40 \\
(0.387)\end{array}$ & & & & $\begin{array}{c}0.65 \\
(0.400)\end{array}$ \\
\hline $\mathrm{RV}$ & & $\begin{array}{c}0.67 * \\
(0.258)\end{array}$ & & $\begin{array}{c}0.57 * \\
(0.260)\end{array}$ & & & & $\begin{array}{c}-0.49 \\
(0.443)\end{array}$ \\
\hline EXLT & & & $\begin{array}{c}0.16^{*} \\
(0.072)\end{array}$ & $\begin{array}{c}0.11 \\
(0.075)\end{array}$ & & & & $\begin{array}{c}0.12 \\
(0.078)\end{array}$ \\
\hline Emp. Growth & & & & & & & & $\begin{array}{c}0.14 * * \\
(0.039)\end{array}$ \\
\hline Emp. Growth, lagged & & & & & & $\begin{array}{c}0.03 \\
(0.027)\end{array}$ & & \\
\hline Emp. Growth, forward & & & & & & & $\begin{array}{c}0.05 \\
(0.031)\end{array}$ & \\
\hline Entry rate & & & & & $\begin{array}{c}-0.07 \\
(0.074)\end{array}$ & & & $\begin{array}{c}-0.09 \\
(0.068)\end{array}$ \\
\hline Exit rate & & & & & $\begin{array}{c}0.12 * \\
(0.045)\end{array}$ & & & $\begin{array}{c}0.04 \\
(0.061)\end{array}$ \\
\hline Pop. (in mn.) & $\begin{array}{l}0.01 * * \\
(0.003)\end{array}$ & $\begin{array}{l}0.01 * * \\
(0.002)\end{array}$ & $\begin{array}{l}0.01 * * \\
(0.003)\end{array}$ & $\begin{array}{l}0.01 * * \\
(0.002)\end{array}$ & $\begin{array}{l}0.01 * * \\
(0.003)\end{array}$ & $\begin{array}{l}0.01 * * \\
(0.003)\end{array}$ & $\begin{array}{l}0.01 * * \\
(0.004)\end{array}$ & $\begin{array}{c}0.01 \\
(0.023)\end{array}$ \\
\hline Constant & $\begin{array}{l}0.02 * * \\
(0.002)\end{array}$ & $\begin{array}{c}0.00 \\
(0.010)\end{array}$ & $\begin{array}{c}0.01 \\
(0.006)\end{array}$ & $\begin{array}{c}-0.01 \\
(0.013)\end{array}$ & $\begin{array}{l}0.02^{* * *} \\
(0.003)\end{array}$ & $\begin{array}{l}0.03^{* *} \\
(0.002)\end{array}$ & $\begin{array}{l}0.02 * * \\
(0.002)\end{array}$ & $\begin{array}{c}0.00 \\
(0.013)\end{array}$ \\
\hline Time effects & $\mathrm{Y}$ & $\mathrm{Y}$ & $\mathrm{Y}$ & $\mathrm{Y}$ & $\mathrm{Y}$ & $\mathrm{Y}$ & $\mathrm{Y}$ & $\mathrm{Y}$ \\
\hline Observations & 210 & 210 & 210 & 210 & 210 & 175 & 175 & 210 \\
\hline R-squared & 0.170 & 0.230 & 0.196 & 0.243 & 0.181 & 0.154 & 0.203 & 0.181 \\
\hline
\end{tabular}

Note: This table shows the robustness checks of the regression results explaining regional HGF shares. OLS denotes ordinary least squares, FE denotes fixed effects. Standard errors clustered at the NUTS-3 level in parentheses in the OLS regressions; Significance levels: ** $\mathrm{p}<0.01, * \mathrm{p}<0.05,+\mathrm{p}<0.1$; within- $\mathrm{R}^{2}$ is reported for the FE specification. 
Table B2. HGF shares unconditionally regressed on the lagged HGF share

\begin{tabular}{lc} 
Dep. Var. & HGF \\
\hline & \\
AR1 & $0.40 * *$ \\
& $(0.075)$ \\
Constant & $0.02 * *$ \\
& $(0.002)$ \\
& \\
Observations & 175 \\
R-squared & 0.154
\end{tabular}

Note: This table shows OLS regression results. Standard errors clustered at the NUTS-3 level in parentheses; ** $\mathrm{p}<0.01, * \mathrm{p}<0.05,+\mathrm{p}<0.1$; within- $\mathrm{R}^{2}$ reported in specification $(6)$ 


\section{Distributions of growth rates}

To provide an overview of the growth rate distribution, we follow Bravo-Biosca et al. (2010), and create eleven growth brackets to which we assign firms according to their annualised growth rate over three years. We begin with firms that decline at an average annual rate of more than $20 \%$ on the far left-hand side; firms that are stagnant and quasi stagnant are in the middle. On the right-hand side, there are high-growth firms as defined above. The box plot of the growth rate distribution in Figure A1 presents the average growth distribution over all regions and all six non-overlapping three-year periods.

The bulk of firms display modest growth rates. They are in the middle of the firm growth rate distribution, i.e., they exhibit no or little growth $(-5 \%<$ growth $<5 \%)$ and can be considered as stable firms. On average $52.1 \%$ of all firms with more than 10 employees at the beginning of the respective period fall into this bracket. The standard deviation is $2.3 \%$. An expanded medium growth bracket $(-10 \%<$ growth $<10 \%)$ bins approximately $76.8 \%$ of all firms (standard deviation: $2.4 \%$ ). Firms that grow faster than $20 \%$ annually account for $2.7 \%$ of the sample. This fraction of the sample corresponds to the OECD-Eurostat definition of HGFs. High decline firms (firms that reduce their employment at an annualised rate greater than $20 \%$ over three years) made for $5.1 \%$ of all firms (Figure 2). 


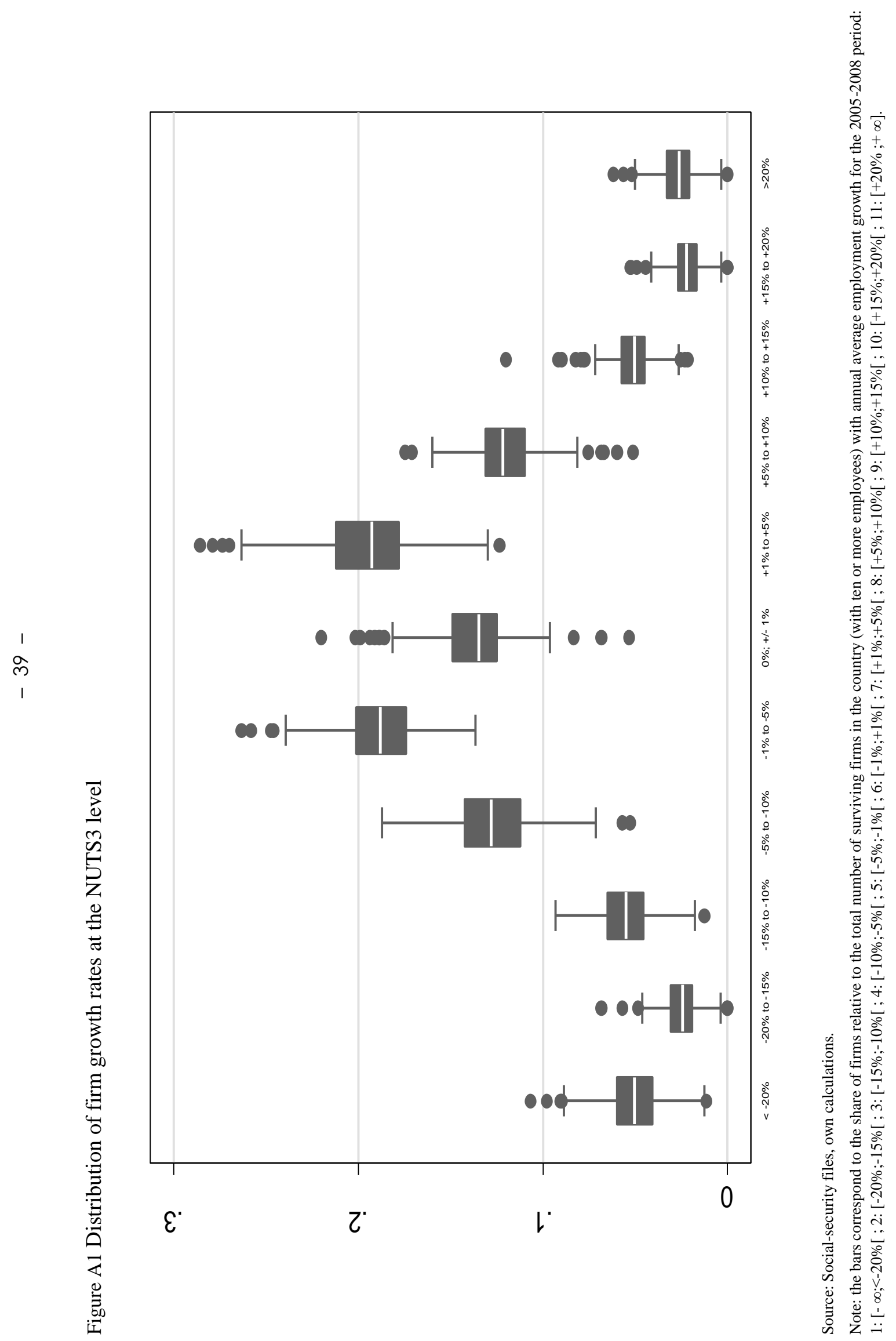

